\title{
Enzymatic Construction of Protein Polymer/Polyprotein Using OaAEP1 and TEV Protease
}

\author{
Yibing Deng, Shengchao Shi, Bin Zheng, Tao Wu and Peng Zheng*
}

State Key Laboratory of Coordination Chemistry, School of Chemistry and Chemical Engineering, Nanjing University, Nanjing, Jiangsu, 21002, China

*For correspondence: pengz@nju.edu.cn

\begin{abstract}
[Abstract] The development of chemical and biological coupling technologies in recent years has made possible of protein polymers engineering. We have developed an enzymatic method for building polyproteins using a protein ligase OaAEP1 (asparagine endopeptidase 1) and protease TEV (tobacco etching virus). Using a mobile TEV protease site compatible with the OaAEP1 ligation, we achieved a stepwise polymerization of the protein on the surface. The produced polyprotein can be verified by protein unfolding scenario using atomic force microscopy-based single-molecule force spectroscopy (AFM-SMFS). Thus, this study provides an alternative method for polyprotein engineering and immobilization.
\end{abstract}

Keywords: Polymerization, Enzyme, Single-molecule force spectroscopy, Polyprotein engineering, OaAEP1

[Background] Several methods based on biochemical reactions for protein polymerization have been developed. For example, one approach is to design protein monomer with additional cysteines as the basic unit for ligation (Dietz et al., 2006; Durner et al., 2017). Another approach is to build the complete gene for the artificial protein oligomer (Carrion-Vazquez et al., 1999; Giganti et al., 2018). However, the engineering of large-sized protein polymer is often challenging. To address this challenge, we have developed an enzyme-mediated method that builds protein polymers/polyproteins in a stepwise fashion, using protein ligase and protease (Yang et al., 2017; Deng et al., 2019). When a TEV site (ENLYFQ/G) plus a leucine (L) is designed as ENLYFQ/GL-POI (POI: Protein of Interest) at the N-terminus of the protein unit, TEV cleavage produces an N-terminal GL residue of GL-POI, which is compatible with further OaAEP1 ligation. Our enzymatic method provides a new method for the preparation of the polyprotein sample with a controlled sequence and suitable for single-molecule studies, especially for complex protein systems.

The engineered polyprotein sequence is confirmed by individual protein unfolding event using AFMSMFS. Besides a powerful imaging tool (Mannix et al., 2018), AFM can manipulate single molecule mechanically and directly measure its unfolding, unbinding, and rupture force (He et al., 2012; Scholl and Marszalek, 2018; Zhang et al., 2019). Thus, it is widely used to study protein (un)folding and mechanics (Infante et al., 2019; Krieg et al., 2019), protein-protein/ligand-receptor interaction (Ott et al., 2017; Zhang et al., 2019) and even chemical bond (Pill et al., 2019; Song et al., 2019; Yuan et al., 2019). Together with other established polyprotein engineering and immobilization methods (Dietz et al., 2006; Popa et al., 2013; Hoffmann et al., 2015; Walder et al., 2017), our enzymatic methodology can improve 
the quality and efficiency of SMFS study.

\section{Materials and Reagents}

1. Glass coverslip (Sail Brand, China)

2. E. coli BL21(DE3) $\left(-80^{\circ} \mathrm{C}\right)$

3. $\mathrm{pQE80L-POI}$ or $\mathrm{pET} 28 \mathrm{a}-\mathrm{POI}$ plasmid (Vector information in the Supplemetal file)

4. Milli-Q water $(18.2 \mathrm{M} \Omega / \mathrm{cm})$

5. Luria-Bertani (LB) medium (BD Difco)

6. Iron (III) chloride hexahydrate (99\%, Energy chemical)

7. Calcium chloride hydrate crystalline aggregate (99.9965\%, Alfa Aesar)

8. (3-aminopropyl) triethoxysilane (APTES, 99\%, Sigma-Aldrich)

9. Sulfosuccinimidyl 4-(N-maleimidomethyl) cyclohexane-1-carboxylate (sulfo-SMCC, Thermo Scientific)

10. Sodium chloride $(\mathrm{NaCl})(99 \%, \mathrm{BBL}$ Life Science)

11. Tris(hydroxymethyl) aminomethane (Tris, $>99.9 \%$, Sangon Biotech)

12. EDTA (99.5\%, Macklin)

13. $5,5^{\prime}$-Dithiobis (2-nitrobenzoic Acid) (99\%, Alfa Aesar)

14. Ampicillin sodium salt (99\% Zhu YanBIO)

15. Kanamycin ( $\geq 750 \mu \mathrm{g} / \mathrm{mg}$, Diamond)

16. Magnesium sulfate $\left(\mathrm{MgSO}_{4}\right)$ (AR, Shanghai Lingfeng Chemical Reagent Co., Ltd)

17. Calcium chloride $\left(\mathrm{CaCl}_{2}\right)$ (AR, Aladdin)

18. $\mathrm{D}(+)$-Glucose (AR, Aladdin)

19. IPTG (Isopropyl- $\beta$-d-thiogalactopyranoside) (99\% Zhu YanBIO)

20. DNase (from Bovine Pancreas, Activity $\geq 500$ Kunitz U/mg, Sangon Biotech)

21. RNase (from Bovine Pancreas, Activity $\geq 60 \mathrm{U} / \mathrm{mg}$, Sangon Biotech)

22. PMSF (Zhu YanBIO)

23. Potassium chromate $(99.5 \%$, Macklin)

24. Concentrated sulfuric acid (AR, Sinopharm Chemical Reagent Co.,Ltd)

25. Ethyl alcohol (AR, Sinopharm Chemical Reagent Co.,Ltd)

26. Imidazole (99\% Aladdin)

27. Urea (AR, Sinopharm Chemical Reagent Co.,Ltd)

28. TEV protease (produced by ourselves)

29. OaAEP1 (produced by ourselves)

30. BamHI (TaKaRa)

31. Bg/ll (TaKaRa)

32. Kpnl (TaKaRa)

33. T4 Ligase (TaKaRa)

34. Glycerol (99\%, Macklin) 
35. M9 medium (see Recipes)

36. Chromic acid (see Recipes)

37. Lysis buffer (see Recipes)

38. Wash buffer (see Recipes)

39. Elution buffer (see Recipes)

40. DTNB solution (see Recipes)

41. TEV protease solution (see Recipes)

42. AFM measurement buffer (see Recipes)

\section{Equipment}

1. Avanti JXN-30 Centrifuge (Beckman Coulter)

2. AKTA FPLC system (GE Healthcare)

3. Mono Q $5 / 50 \mathrm{GL}$ (GE Healthcare)

4. NanoDrop 2000 spectrophotometer (Thermo Scientific)

5. Nanowizard 4 AFM (JPK Instruments AG)

6. Silicon nitride cantilever (MLCT, Bruker Corp)

7. Sonictor (Biosafer 650-92)

\section{Software}

1. JPK data processing (developed by JPK Instruments AG)

2. Igor Pro 6.12 (Wavemetrics)

\section{Procedure}

A. Gene cloning

1. Use three-restriction digestion enzyme system BamHI-POI-Bg/ll-stop codon-Kpnl for connecting the gene of different protein fragments. In this enzyme system use Bg/ll and Kpnl digest to produce vector and use BamHI and Kpnl digest to produce the insert. As BamHI digestion and Bg/ll digestion leads to the same cohesive end (GATC), it is possible to use T4 ligase connect the vector and the insert.

2. Confirm all genes by sequencing.

B. Expression and production of interest proteins

Note: In the experimental operation, always pay attention to the aseptic operation. Different proteins have different $E$. coli harvest shelf life. It is necessary to test the shelf life for the specific protein.

1. Transform the PQE80L-POI or pET28a-POI plasmid into E. coli BL21(DE3) cell. 
2. Apply the bacterial solution to the LB plate containing ampicillin sodium salt ( $100 \mu \mathrm{g} / \mathrm{ml})$ for pQE80L plasmid or kanamycin $(50 \mu \mathrm{g} / \mathrm{ml})$ for pET28a plasmid and incubate at $37^{\circ} \mathrm{C}$ for $14-16$ h.

3. Pick single colonies into $15 \mathrm{ml}$ LB medium containing ampicillin sodium salt $(100 \mu \mathrm{g} / \mathrm{ml})$ or kanamycin $(50 \mu \mathrm{g} / \mathrm{ml})$. Keep shaking at $200 \mathrm{rpm}$ at $37^{\circ} \mathrm{C}$ for $16-20 \mathrm{~h}$.

4. After grown saturation, dilute the overnight cultures into $800 \mathrm{ml}$ fresh LB media (add to the LB medium in a ratio of 1:50) containing respective antibiotics (the concentration of antibiotics is the same as above). As for the metalloprotein, centrifuged the culture at $1,800 \times g$ and resuspended the precipitation by $16 \mathrm{ml} \mathrm{M9}$ medium, and then add to $800 \mathrm{ml}$ respective antibiotics containing M9 medium as well.

5. Shake culture at $200 \mathrm{rpm}$ at $37{ }^{\circ} \mathrm{C}$ until the optical density at $600 \mathrm{~nm}\left(\mathrm{OD}_{600}\right)$ reaches $0.6-0.8$ (this takes about 2.5-3 h, while M9 medium always takes about 5-6 h). Reserve a 100- $\mu$ l sample of the culture as the pre-induction control for testing protein expression.

6. Add IPTG (Isopropyl- $\beta$-d-thiogalactopyranoside) to a final concentration of $1 \mathrm{mM}$ to induce protein expression, while metalloprotein always needs some additional metal ion, and shake the culture at $200 \mathrm{rpm}$ at $37^{\circ} \mathrm{C}$ for $4-6 \mathrm{~h}$.

7. Harvest the culture at $13,000 \times \mathrm{g}$ for $25 \mathrm{~min}$ at $4{ }^{\circ} \mathrm{C}$ and store at $-80^{\circ} \mathrm{C}$ before purification.

C. Purification of interest proteins

1. Resuspend the cells in $25 \mathrm{ml}$ lysis buffer (contained $0.06 \mathrm{mg}$ DNase, $0.06 \mathrm{mg}$ RNase, $0.08 \mathrm{mg}$ PMSF) and produce the lysis using a Biosafer sonicator (15\% amplitude) on ice for $30 \mathrm{~min}$. Clarify the cell lysate at $19,600 \times g$ for $40 \mathrm{~min}$ at $4{ }^{\circ} \mathrm{C}$ and collect the supernatant fraction.

2. Pack a Poly-Prep column with $1-1.5 \mathrm{ml}$ (bed volume) of Co-NTA or Ni-NTA affinity column and wash it with ten column volumes (CV) of Milli-Q water and then $10 \mathrm{CVs}$ wash buffer (by gravity flow).

3. Load the supernatant onto the column by gravity flow and collect the flow-through. Load the flow-through onto the column by gravity and collect the secondary flow-through. Load the secondary flow-through onto the column by gravity and finish the sample loading.

4. Wash the column with $50 \mathrm{CVs}$ of wash buffer.

5. Elute the bound protein with $3 \mathrm{CVs}$ of elution buffer at $4{ }^{\circ} \mathrm{C}$ for $15 \mathrm{~min}$. Moreover, carry out anion exchange purification for pure metal form rubredoxin protein using AKTA with Mono $Q$ column at $\mathrm{pH} 8.5$ at $4{ }^{\circ} \mathrm{C}$.

6. Analyze the samples of the eluate and control group by SDS-PAGE.

7. Use the Ellman method to confirm the concentration of ELPs, in which $10 \mu \mathrm{l}$ protein incubated with $20 \mu \mathrm{L}$ DTNB solution for $30 \mathrm{~min}$ at room temperature and the solution composited with $10 \mu \mathrm{l}$ the elution buffer solution and $20 \mu \mathrm{l}$ DTNB solution served as blank to detect the absorbance of protein and DTNB reaction solution at $412 \mathrm{~nm}\left(\varepsilon=13,700 \mathrm{M}^{-1} \mathrm{~cm}^{-1}\right)$ by NanoDrop 2000 spectrophotometer. 
D. Functionalized coverslip surface preparation

Note: The functionalized coverslip should be immediately used or stored at $4^{\circ} \mathrm{C}$ for a month after preparation.

1. Clean and activate glass coverslips by immersing in chromic acid at $80{ }^{\circ} \mathrm{C}$ for $30 \mathrm{~min}$. Wash away chromic acid traces on the coverslips by water and then ethyl alcohol. Dry the coverslips by a stream of nitrogen.

2. Aminosilylate the coverslips by immersing them in $1 \%(\mathrm{v} / \mathrm{v})$ APTES toluene solution for $1 \mathrm{~h}$ at room temperature avoiding light.

3. Wash the coverslips with toluene and absolute ethyl alcohol and dry the coverslips with nitrogen.

4. Bake the coverslips at $80^{\circ} \mathrm{C}$ for $15 \mathrm{~min}$.

5. Add $200 \mu \mathrm{l}$ sulfo-SMCC ( $1 \mathrm{mg} / \mathrm{ml}$ ) dimethyl sulfoxide (DMSO) solution between two immobilized coverslips after the coverslips cooling down to room temperature and incubate for $1 \mathrm{~h}$ protected from light at room temperature.

6. Wash every piece of the coverslips with $15 \mathrm{ml}$ DMSO first and then with absolute ethyl alcohol to remove residual sulfo-SMCC. Use a stream of nitrogen to dry the coverslips.

7. Stick cleaned quartz ring on the functioned side of the coverslip to build a chamber.

8. Pipet $200 \mu \mathrm{l}$ of $200 \mu \mathrm{M} \mathrm{GL}-E_{L} P_{50 n m}-C$ protein solution onto the functionalized coverslip in the chamber and incubate for approximately $3 \mathrm{~h}$.

9. Wash the chamber with Milli-Q water to remove the unreacted GL-ELP50nm-C.

E. Functionalized cantilevers surface preparation

Note: Silicon nitride cantilever was used as a force probe. The surface chemistry of the cantilevers was similar to that of the coverslip.

1. Immerse the cantilevers at $80{ }^{\circ} \mathrm{C}$ for $10 \mathrm{~min}$ by chromic acid treatment. Remove the traces of chromic acid by water first and then ethyl alcohol. Use a piece of filter paper blot ethyl alcohol traces up.

2. Functionalize the cleaned cantilevers by amino-silanization with APTES and then conjugate the cantilevers to sulfo-SMCC as the method mentioned in Section D, Functionalized coverslip surface preparation.

3. Immerse the functionalized cantilever with Cys-ELP ${ }_{50 n m}-N G L$ at the concentration of $200 \mu \mathrm{M}$ to the surface with maleimide group of sulfo-SMCC for $1.5 \mathrm{~h}$.

4. Wash the coverslip with Milli-Q water to remove the unreacted Cys-ELP $50 \mathrm{~nm}-\mathrm{NGL}$ and store the cantilever at $-20^{\circ} \mathrm{C}$.

5. Before the AFM experiment, immerse a ELP-functionalized cantilever in $50 \mu \mathrm{M}$ GL-CBM-XDoc protein solution with $200 \mathrm{nM}$ OaAEP1 for $20-30 \mathrm{~min}$ at $25^{\circ} \mathrm{C}$, and then wash away the unreacted proteins by $15-20 \mathrm{ml}$ AMF buffer.

F. Stepwise polyprotein preparation with controlled sequences Note: Use 15-20 ml AFM buffer to wash away residual proteins after each reaction step. Figure 1 
presents the schematic diagram of the controlled sequence polyprotein preparation.

1. Mix unit Coh-tev-L-POI-NGL $(50 \mu \mathrm{M})$ and OaAEP1 $(200 \mathrm{nM})$ and add $60 \mu$ lo the functionaliazed coverslip. link the ligation unit Coh-tev-L-POI-NGL to the functionalized coverslip.

2. Add $100 \mu \mathrm{l} \mathrm{TEV} \mathrm{protease} \mathrm{solution} \mathrm{to} \mathrm{cleave} \mathrm{the} \mathrm{TEV} \mathrm{site} \mathrm{in} \mathrm{the} \mathrm{protein} \mathrm{unit} \mathrm{for} \mathrm{about} 1 \mathrm{~h}$ at $25^{\circ} \mathrm{C}$. And GL-Ub-NGL-glass will produce with exposed N-terminal GL residues.

3. Repeat Steps F1-F2 (N-1) times to get the protein-polymer GL-(Ub)N-NGL-Glass. After OaAEP ligation of the final ligation unit, do not take the TEV cleavage reaction to obtain Coh-tev-L$(\mathrm{Ub})_{n}$-NGL-Glass.

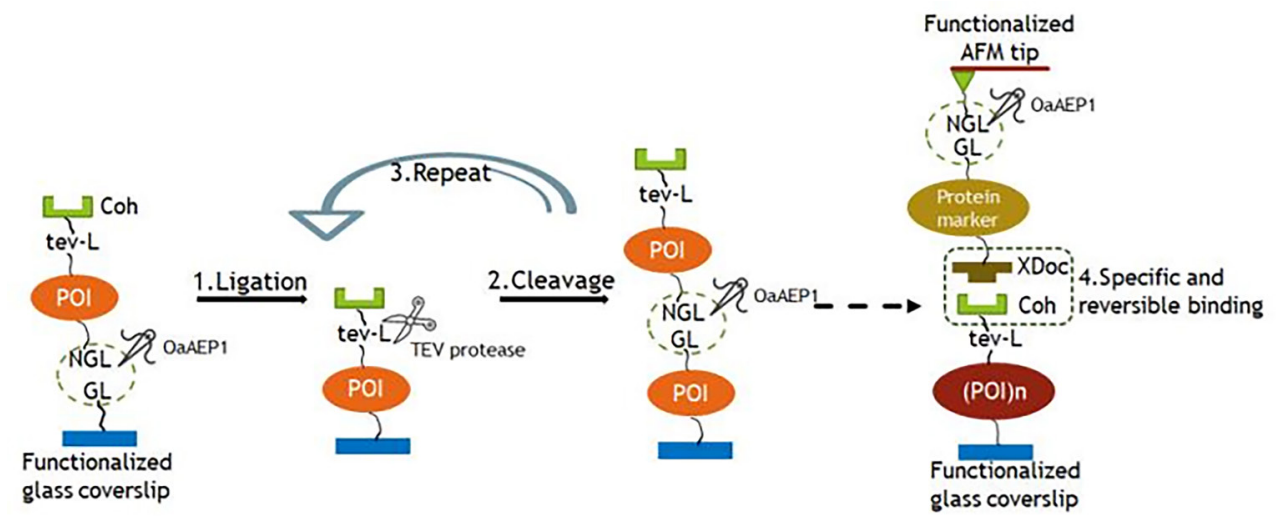

Figure 1. The schematic displays the stepwise ligation and cleavage procedure to produce sequence-controlled polyprotein on the glass surface and probed with an XDocprotein maker-modified cantilever

G. AFM measurements

Note: The AFM experiment parameters ( $Z$ length, $Z$ speed, setpoint, sample rate and duration time) are adjustable in different experiments.

1. Add $1 \mathrm{ml} \mathrm{AFM} \mathrm{buffer} \mathrm{containing} 10 \mathrm{mM} \mathrm{CaCl}_{2}$ to the chamber (Figure 2).

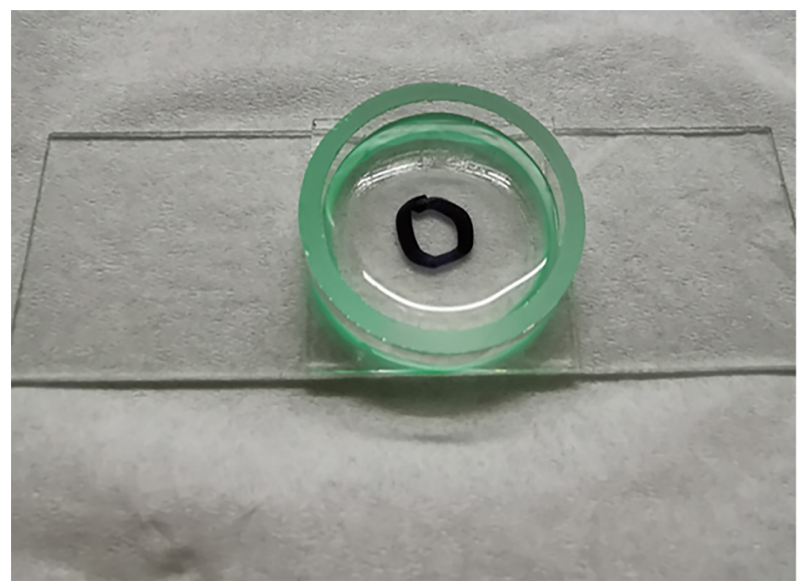

Figure 2. A photo image about AFM chamber with $1 \mathrm{ml} \mathrm{AFM} \mathrm{buffer} \mathrm{solution.} \mathrm{The} \mathrm{black} \mathrm{ring}$ shows the position of the polyprotein. 
2. Move the laser to the $D$ tip of the functionalized probe (Figure 3). Use the equipartition theorem to calibrate the spring constant $(\mathrm{K})$ of each cantilever in solution with an accurate value before the experiment.

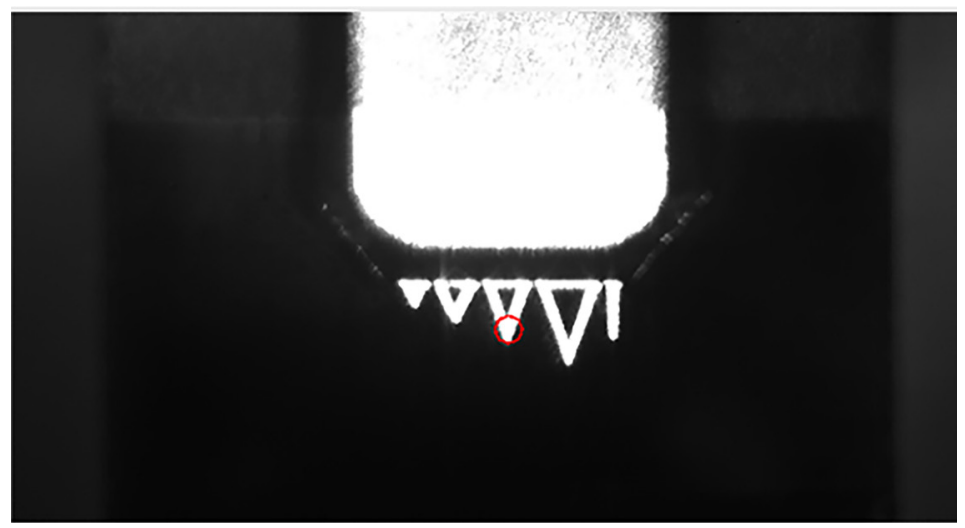

Figure 3. CCD picture of the cantilever tip in the AFM experiment. The triangle which the red ring located is $D$ tip. The red ring points out the lase radiation position on $D$ tip.

3. The cantilever tip attached to the sample surface and hold at this position for a while to formed the cohesin/dockerin pair as shown in Figure 4, segment 0 and segment 1.

4. Retracted the cantilever from the surface at a constant velocity of $400 \mathrm{~nm} \mathrm{~s}^{-1}$ while recording the distance and cantilever deflection at a sampling rate of 4,096 Hz. As shown in Figure 4, segment 2.

5. Hold the cantilever for a while to relax the cohesin/dockerin pair as shown in Figure 4, segment 3.

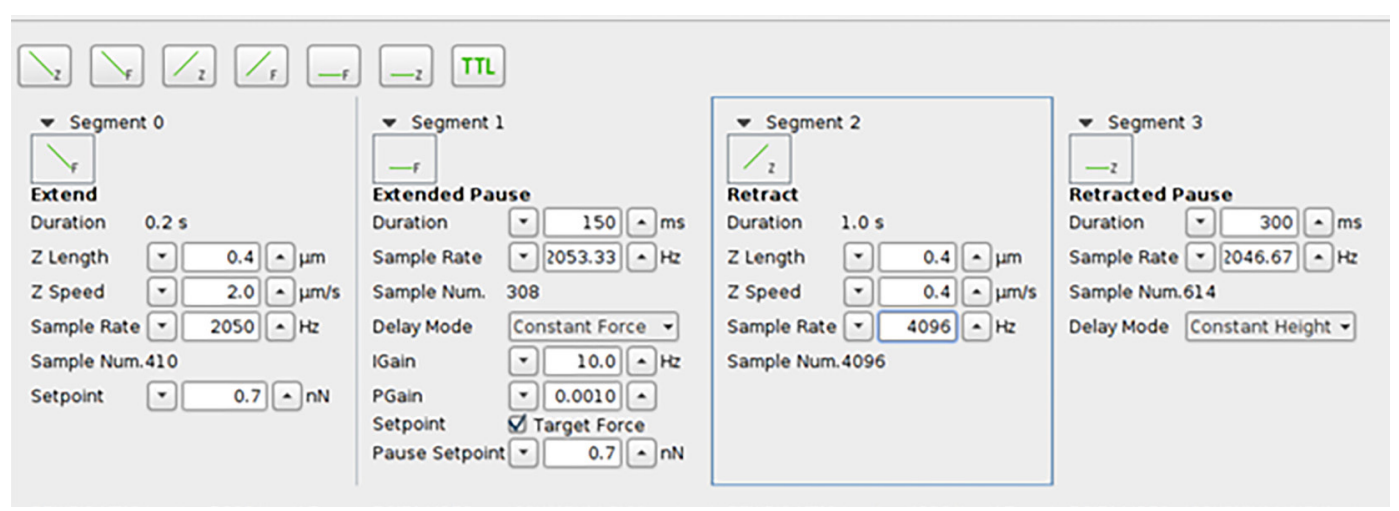

Figure 4. The dialog about the AFM experiment parameter setting. One AFM measurement contain four step. Segment 0 makes cantilever move towards the sample surface. Segment 1 keep the cantilever staying at the height reached by segment 0 for duration time. Segment 2 retract the cantilever from the surface and the protein unfold during this period. Segment 3 keep the cantilever at the height reached by segment 2 for duration time. 


\section{Data analysis}

1. Use JPK data processing select force-extension traces.

2. Use Igor Pro 6.12 (Wavemetrics) analysis the data traces. Only the data traces containing all the specific contour length increments belong to fingerprint protein domains [GB1 $(\mathrm{H} 18 \mathrm{~nm})$ and CBM (H58 nm)] and a high rupture force from the cohesin-dockerin dissociation meet the requirement (more than 200-300 pN) (Figure 5). Fit The curves by the worm-like-chain (WLC) model of polymer elasticity with the persistence length of $\sim 0.4 \mathrm{~nm}$.

3. Use Gauss model fit the histograms of unfolding forces to determine values of the most probable unfolding force $(<F>)$ and contour length increment $(<\Delta L c>)$.

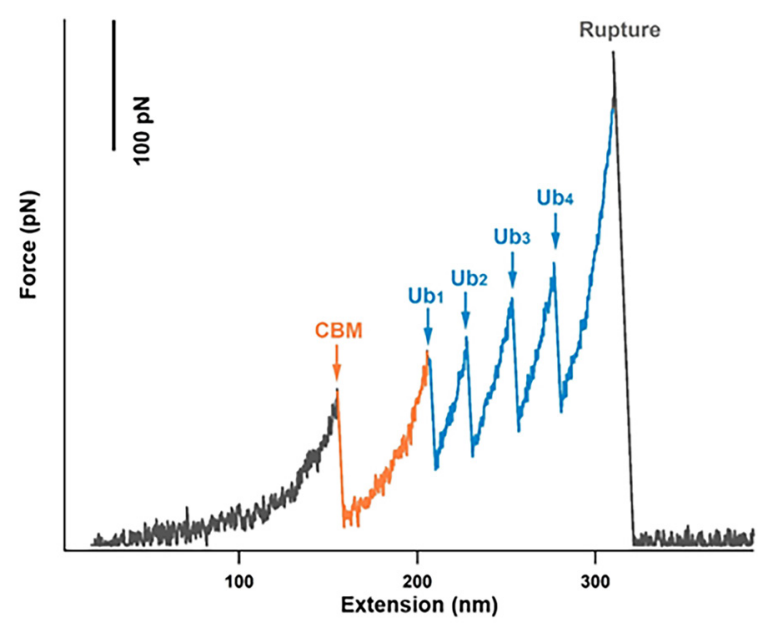

Figure 5. Typical force versus distance trace for the sequence-controlled polyprotein, Coh-Ub $b_{4}$, containing signals of CBM unfolding, dockerin-cohesin pair rupture and four copies of Ub

\section{Recipes}

1. Lysis buffer

$50 \mathrm{mM}$ Tris

$150 \mathrm{mM} \mathrm{NaCl}$

$\mathrm{pH} 7.4$

2. Wash buffer

$20 \mathrm{mM}$ Tris

$400 \mathrm{mM} \mathrm{NaCl}$

$2 \mathrm{mM}$ imidazole

$\mathrm{pH} 7.4$

3. Elution buffer

$20 \mathrm{mM}$ Tris 
$400 \mathrm{mM} \mathrm{NaCl}$

$250 \mathrm{mM}$ imidazole

$\mathrm{pH} 7.4$

4. DTNB solution

$0.5 \mathrm{mM}$ 5,5'-Dithiobis (2-nitrobenzoic Acid)

$1 \mathrm{mM}$ EDTA

7.2 M Urea

5. TEV protease solution

$0.4 \mathrm{mg} / \mathrm{ml}$ TEV protease

$75 \mathrm{mM} \mathrm{NaCl}$

$0.5 \mathrm{mM}$ EDTA

$25 \mathrm{mM}$ Tris- $\mathrm{HCl}, \mathrm{pH} 8.0$

$10 \%[\mathrm{v} / \mathrm{v}]$ glycerol

6. AFM measurement buffer

$100 \mathrm{mM}$ Tris

$100 \mathrm{mM} \mathrm{NaCl}$

$\mathrm{pH} 7.4$

7. Chromic acid

$20 \mathrm{~g}$ potassium chromate

$40 \mathrm{ml}$ ultrapure water

$360 \mathrm{ml}$ concentrated sulfuric acid

8. M9 medium

$0.4 \%$ glucose

$0.1 \mathrm{mM} \mathrm{CaCl}_{2}$

$2 \mathrm{mM} \mathrm{MgSO}_{4}$

\section{Acknowledgments}

National Natural Science Foundation of China (Grant Nos. 21771103, 21977047), Natural Science Foundation of Jiangsu Province (Grant No. BK20160639). This protocol was modified from previous work "Enzymatic biosynthesis and immobilization of polyprotein verified at the single-molecule level (Deng et al., 2019).

\section{Competing interests}

The authors declare no conflict of interest. 


\section{References}

1. Carrion-Vazquez, M., Oberhauser, A. F., Fowler, S. B., Marszalek, P. E., Broedel, S. E., Clarke, J. and Fernandez, J. M. (1999). Mechanical and chemical unfolding of a single protein: A comparison. Proc Natl Acad Sci U S A 96(7): 3694-3699.

2. Deng, Y., Wu, T., Wang, M., Shi, S., Yuan, G., Li, X., Chong, H., Wu, B. and Zheng, P. (2019). Enzymatic biosynthesis and immobilization of polyprotein verified at the single-molecule level. Nat Commun 10(1): 2775.

3. Dietz, H., Bertz, M., Schlierf, M., Berkemeier, F., Bornschlogl, T., Junker, J. P. and Rief, M. (2006). Cysteine engineering of polyproteins for single-molecule force spectroscopy. Nat Protoc 1(1): 80-84.

4. Durner, E., Ott, W., Nash, M. A. and Gaub, H. E. (2017). Post-translational sortase-mediated attachment of high-strength force spectroscopy handles. Acs Omega 2(6): 3064-3069.

5. Giganti, D., Yan, K., Badilla, C. L., Fernandez, J. M. and Alegre-Cebollada, J. (2018). Disulfide isomerization reactions in titin immunoglobulin domains enable a mode of protein elasticity. $\mathrm{Nat}$ Commun 9(1): 185.

6. He, C., Genchev, G. Z., Lu, H. and Li, H. (2012). Mechanically untying a protein slipknot: multiple pathways revealed by force spectroscopy and steered molecular dynamics simulations. J Am Chem Soc 134(25): 10428-10435.

7. Hoffmann, T., Tych, K. M., Crosskey, T., Schiffrin, B., Brockwell, D. J. and Dougan, L. (2015). Rapid and robust polyprotein production facilitates single-molecule mechanical characterization of $\beta$-Barrel assembly machinery polypeptide transport associated domains. ACS Nano 9(9): 8811-8821.

8. Infante, E., Stannard, A., Board, S. J., Rico-Lastres, P., Rostkova, E., Beedle, A. E. M., Lezamiz, A., Wang, Y. J., Gulaidi Breen, S., Panagaki, F., Sundar Rajan, V., Shanahan, C., Roca-Cusachs, P. and Garcia-Manyes, S. (2019). The mechanical stability of proteins regulates their translocation rate into the cell nucleus. Nat Phys 15: 973-981.

9. Krieg, M., Fläschner, G., Alsteens, D., Gaub, B. M., Roos, W. H., Wuite, G. J. L., Gaub, H. E., Gerber, C., Dufrêne, Y. F. and Müller, D. J. (2019). Atomic force microscopy-based mechanobiology. Nat Rev Phys 1(1): 41-57.

10. Mannix, A. J., Zhang, Z. H., Guisinger, N. P., Yakobson, B. I. and Hersam, M. C. (2018). Borophene as a prototype for synthetic 2D materials development. Nat Nanotech 13(6): 444450.

11. Ott, W., Jobst, M. A., Schoeler, C., Gaub, H. E. and Nash, M. A. (2017). Single-molecule force spectroscopy on polyproteins and receptor-ligand complexes: The current toolbox. J Stru Bio 197(1): 3-12.

12. Pill, M. F., East, A. L. L., Marx, D., Beyer, M. K. and Clausen-Schaumann, H. (2019). Mechanical activation drastically accelerates amide bond hydrolysis, matching enzyme activity. Angew Chem Int Ed 58(29): 9787-9790. 
13. Popa, I., Berkovich, R., Alegre-Cebollada, J., Badilla, C. L., Rivas-Pardo, J. A., Taniguchi, Y., Kawakami, M. and Fernandez, J. M. (2013). Nanomechanics of HaloTag Tethers. J Am Chem Soc 135(34): 12762-12771.

14. Scholl, Z. N. and Marszalek, P. E. (2018). AFM-based single-molecule force spectroscopy of proteins. Methods Mol Biol 1814: 35-47.

15. Song, Y., Ma, Z., Yang, P., Zhang, X., Lyu, X., Jiang, K. and Zhang, W. (2019). Single-molecule force spectroscopy study on force-induced melting in polymer single crystals: the chain conformation matters. Macromolecules 52(3): 1327-1333.

16. Walder, R., LeBlanc, M. A., Van Patten, W. J., Edwards, D. T., Greenberg, J. A., Adhikari, A., Okoniewski, S. R., Sullan, R. M. A., Rabuka, D., Sousa, M. C. and Perkins, T. T. (2017). Rapid characterization of a mechanically labile $\alpha$-helical protein enabled by efficient site-specific bioconjugation. J Am Chem Soc 139(29): 9867-9875.

17. Yang, R., Wong, Y. H., Nguyen, G. K. T., Tam, J. P., Lescar, J. and Wu, B. (2017). Engineering a catalytically efficient recombinant protein ligase. J Am Chem Soc 139(15): 5351-5358.

18. Yuan, G., Liu, H., Ma, Q., Li, X., Nie, J., Zuo, J. and Zheng, P. (2019). Single-molecule force spectroscopy reveals that iron-ligand bonds modulate proteins in different modes. $J$ Phys Chem Lett 10(18): 5428-5433.

19. Zhang, S., Qian, H.-j., Liu, Z., Ju, H., Lu, Z.-y., Zhang, H., Chi, L. and Cui, S. (2019). Towards unveiling the exact molecular structure of amorphous red phosphorus by single-molecule studies. Angew Chem Int Ed 58(6): 1659-1663. 